\title{
Estradiol Mustard
}

National Cancer Institute

\section{Source}

National Cancer Institute. Estradiol Mustard. NCI Thesaurus. Code C38115.

A conjug ate of two agents, estradiol and an alkylating mustard (usually mechlorethamine or non-nitrogen mustard). Estramustine is one such agent (see Estramustine Phosphate Sodium). ( $\mathrm{NClO4)}$ 